\title{
Pediatric Dentists' Educational Experiences, Attitudes, and Professional Behavior Concerning Resin Infiltration: Implications for Dental Education
}

\author{
Michael Jordan Halcomb, Marita R. Inglehart, Elisabeta Karl
}

Abstract: Minimally invasive dentistry (MID) is receiving increased attention. Resin infiltration (RI) is one micro-invasive technique for treating initial caries by sealing white spot lesions on tooth surfaces. The aims of this study were to assess pediatric dentists' RI-related educational experiences, attitudes, and professional behavior and to determine if their educational experiences were significantly related to their professional attitudes and behavior regarding RI. This cross-sectional study used an online survey to collect data from members of the American Academy of Pediatric Dentistry (AAPD) in March-April 2017. Of the 2,367 AAPD members invited to participate, 43 emails could not be delivered, and 273 surveys were completed, for a response rate of $11.8 \%$. While only $9 \%$ of the 273 respondents reported that their classroom-based dental education had informed them about RI and only $1 \%$ that it had prepared them well to use RI with pediatric patients, higher percentages said they had been informed/ prepared well by their classroom-based (24\%) and clinical residency education (12\%). The majority wanted to learn more about RI (71\%) and would like to take a related CE course (59\%). The respondents' average RI-related attitudes were positive (on fivepoint scale with 1=worst attitude: Mean=3.84). Regarding use of RI, $28 \%$ of respondents said they used RI sometimes and 4\% often/very often, with $64 \%$ considering implementing RI in their clinics. Graduation year did not correlate with RI attitudes and use. However, the more education about RI the respondents had received during their residency $(r=0.20 ; p<0.01)$ and in professional development after graduation $(\mathrm{r}=0.34 ; \mathrm{p}<0.001)$, the more they used RI in their own work. This study found that the pediatric dentists' RI-related education was positively correlated with their professional behavior. Increasing predoctoral, resident, and continuing professional education about RI should therefore be considered.

Michael Jordan Halcomb, DDS, is an orthodontic resident, Georgia School of Orthodontics; Marita R. Inglehart, Dr phil habil, is the Diversity and Transformation University Professor at the University of Michigan, as well as Professor, Department of Periodontics and Oral Medicine, School of Dentistry, and Adjunct Professor, Department of Psychology, College of Literature, Science, and Arts, University of Michigan; and Elisabeta Karl, DDS, MS, PhD, is Clinical Assistant Professor, Department of Cariology, Restorative Sciences, and Endodontics, School of Dentistry, University of Michigan. Direct correspondence to Dr. Marita R. Inglehart, Department of Periodontics and Oral Medicine, School of Dentistry, University of Michigan, Ann Arbor, MI 48109-1078; 734-763-8073; mri@umich.edu.

Keywords: advanced dental education, pediatric dentistry, restorative dentistry, graduate education, dental residency, attitude, resin infiltration, minimally invasive dentistry, continuing education

Submitted for publication 6/14/19; accepted 9/25/19; first published online 11/11/19 doi: 10.21815/JDE.019.174

I n 2017, Dye et al. used data from the U.S. National Health and Examination Surveys from 1999 through 2004 and from 2011 through 2014 to find that untreated dental caries in primary teeth among two-to-eight-year-old children had decreased from $24 \%$ in the earlier time period to $14 \%$ in the more recent time period. ${ }^{1}$ In contrast, they found little change in the prevalence of carious lesions in older children and adolescents, with 58\% of 12-19-year-old adolescents having had carious lesions in permanent teeth in their earlier publication. ${ }^{2}$ One major consideration in this situation should be to ensure that the treatment provided for these children and adolescents does not only address the current treatment need, but also considers the long-term consequences of the treatment provided. Consequently, a paradigm shift is currently under way, moving from traditional, mostly restorative treatment to approaches that focus on prevention and noninvasive or minimally invasive techniques. While traditional restorations lead to increased tooth structure removal (with further larger restorations eventually following that could even result in loss of tooth vitality), minimally invasive procedures focus on maintaining tooth structure. ${ }^{3}$ The International Caries Classification and Management System (ICCMS) therefore included minimally 
invasive and preventive protocols for low, moderate, and high risk caries activity. ${ }^{4}$ In moderate/high risk patients with an initial carious lesion on either a smooth or proximal surface, experts recommend that topical fluoride application and/or resin sealants or proximal resin infiltration (RI) procedures should be used. ${ }^{4-6}$ In 2018, the new guidelines of the American Dental Association (ADA) recommended the use of RI for interproximal incipient carious lesions. ${ }^{7}$

$\mathrm{RI}$ is a non-invasive intervention, introduced in the 1970s as an alternative treatment to more invasive dental procedures. ${ }^{8}$ RI was designed to occlude the enamel pores of non-cavitated smooth surface carious lesions by first eroding the surface layer of enamel white spot lesions with $15 \%$ hydrochloric acid, followed by low-viscosity light-curing resins (known as "infiltrants"). ${ }^{9}$ The result is a blockage of cariogenic acids and the arrest of lesion progression. ${ }^{10}$ While research showed that RI creates a significantly rougher surface than healthy enamel, clinical trials with a split-mouth design found that RI was effective. ${ }^{11-13}$ For example, in 2010, Ekstrand et al.'s study on primary molars in high caries risk children found, based on radiographs, that only $23.1 \%$ of infiltrated lesions in primary molars had carious lesion progression, while in the control group $61.5 \%$ of lesions had progressed during a 12 -month period. ${ }^{14} \mathrm{In}$ 2012, Meyer-Lueckel et al. showed on radiographs that while only $4 \%$ of infiltrated lesions of young adults with moderate caries risk progressed within a 36-month follow-up period, $46 \%$ of the lesions had progressed in the control group. ${ }^{15}$ A systematic review by Domejean et al. on the effectiveness of RI of non-cavitated lesions concluded in 2015 that RI appeared to be effective in arresting the progression of those lesions. ${ }^{11}$

In 2017, the American Academy of Pediatric Dentistry (AAPD) considered RI in its reference manual and came to the recommendation that there was evidence for using RI as a treatment for small, non-cavitated interproximal carious lesions in permanent teeth. ${ }^{16}$ However, the manual mentioned that most randomized clinical trials on RI had had industry support as a potential conflict of interest. In addition, the AAPD pointed out that RI has benefits when being used to restore white spot lesions formed during orthodontic treatment. In these circumstances, microabrasion techniques may be used before the RI treatment. ${ }^{17,18}$ In 2018, El Meligy et al. concluded in their literature review that RI treatment complements other treatments of interproximal caries by allowing the postponement of traditional and more invasive dental treatments. ${ }^{19}$ Most recently, in 2019, Faghihian et al.'s systematic review and meta-analysis concluded that RI has a "significant advantage over non-invasive preventive measures in arresting initial carious lesions in primary and permanent teeth." 20

In addition to the main advantage of RI that it can be used to treat incipient carious lesions and potentially stop caries progression, which could ultimately lead to the need for caries excavation and use of the drill, ${ }^{21,22}$ there is a second clear advantage for using RI when treating dentally fearful children. Avoiding the need for a high-speed drill has been found to alleviate pediatric patients' dental fear, increase successful dentist-patient interactions, and increase these patients' trust and treatment cooperation. ${ }^{23}$

Given these positive research results, it is not surprising that the ADA established a dental code (D2990) in 2017 for the use of RI for dental treatment. ${ }^{24}$ This fact should motivate dental educators to reflect on the way RI should be covered in predoctoral dental curricula. While no research so far has surveyed dental schools concerning their coverage of RI education in their curricula, one indirect way to gain a better understanding of educational practices could be to survey dental practitioners about their RI-related educational experiences. Given the benefits of the minimally invasive nature of RI use with children, the aims of this study were to assess pediatric dentists' RI-related educational experiences, attitudes, and professional behavior and to determine if their educational experiences were significantly related to their professional attitudes and behavior regarding RI. We will also discuss the implications of these findings for predoctoral and advanced dental education.

\section{Methods}

The Institutional Review Board (IRB) for the Health Sciences and Behavioral Sciences at the University of Michigan determined that this study was exempt from IRB oversight (\#HUM00112874). Participants were members of the AAPD.

We conducted an a priori power analysis with the program package $G^{*}$ Power 3.1.2 (www.psycho. uni-duesseldorf.de/abteilungen/aap/gpower3) to compute the needed sample size, given alpha $=0.05$, the power $=0.95$, and a medium to small effect size of rho $=0.20$, for testing if there were significant relationships between the respondents' educational experiences and their attitudes and RI-related clinical 
behavior/behavioral intentions. This analysis showed that a minimum of 262 subjects would be required to have the power to test the one-sided hypotheses that there were significant relationships among these variables.

For the study, we bought the email addresses of active AAPD members from the AAPD and sent recruitment emails to 2,367 randomly selected members. The recruitment email explained the purpose of the study and provided a link to an anonymous survey on the University of Michigan-Qualtrics website. The data were collected in March and April of 2017. No follow-up emails were sent because the AAPD does not allow sending more than one email to its members.

The questionnaire consisted of four parts. Part 1 asked for information about the respondents' general characteristics, educational experiences, and practice characteristics. Part 2 contained questions concerning the respondents' educational experiences about RI and minimally invasive dentistry. Part 3 was concerned with assessing the respondents' RI-related attitudes. The final set of five questions asked about the respondents' RI use and included two open-ended questions about what the respondents liked and disliked about RI.

The data were analyzed with SPSS, Version 24 (IBM Corp., Armonk, NY, USA). Descriptive statistics such as percentages and means were computed to provide an overview of the responses. Two factor analyses were used to determine underlying factors of the educational items and the attitudinal items (extraction method: principle component analysis; rotation method: Varimax rotation with Kaiser Normalization). The factor analysis of the educational items resulted in six underlying factors and the factor analysis of the attitudinal items in a two-factor solution. Based on the results of the two factor analyses, indices were computed by averaging the responses to the items with factor loadings $>0.40$ on each factor. Cronbach's alpha coefficients were computed to determine the inter-item consistency of the items loading on each factor. All Cronbach's alpha values were over 0.70, indicating that the scales had sufficient to excellent inter-item consistency. ${ }^{25,26}$ Pearson correlation coefficients were used to determine relationships among the educational, attitudinal, and behavioral RI-related responses. Because numerous statistical tests were performed simultaneously when analyzing the relationships among the indices, Bonferroni corrections were used, and the alpha value was lowered to $\mathrm{p}<0.01 .{ }^{27}$

Two independent raters coded the open-ended answers to the questions of what the respondents liked and disliked about RI. The consistency percentages of the coding by Rater 1 and Rater 2 ranged between $87 \%$ and $93 \%$.

\section{Results}

Of the 2,367 AAPD members invited to participate in the survey, 43 emails could not be delivered, and 273 surveys were completed, for a response rate of $11.8 \%$. The 273 respondents were $56 \%$ men and $44 \%$ women and ranged in age from 25 to 74 years (Mean: 46.75 years) (Table 1). The respondents graduated from dental school between 1967 and 2016 and from pediatric dental residency programs between 1969 and 2020. The fact that 2020 was listed as a graduation year from the residency program indicates that two current pediatric dental residents responded. Of the respondents, 39\% worked in a group practice, $30 \%$ in a solo practice, $24 \%$ owned a practice, and $16 \%$ were associates. On average, $38 \%$ of their patients were covered by Medicaid, $45 \%$ by private insurance, and $14 \%$ by self-pay, while $50 \%$ of their patients were under six years of age and $46 \%$ over seven years of age. The respondents saw on average about 111 patients in an average week and worked on average nearly 33 hours per week. When asked about preferred patient management strategies, 53\% reported using nitrous oxide, 7\% oral sedations, $2 \%$ protective stabilization, and $8 \%$ general anesthesia. The ranges of responses to this question showed that some dentists did not use these techniques and that some used them quite frequently when treating pediatric patients.

Table 2 provides an overview of the respondents' educational experiences related to RI and minimally invasive dentistry (MID). The first five questions were related to the respondent's dental school education about RI. Only about $3 \%$ of the respondents strongly agreed and $6 \%$ agreed that their classroom-based dental school education had informed them about the use of RI, and only about $1 \%$ had clinical education about using RI with adult or pediatric patients. Only $4 \%$ agreed/agreed strongly that their dental school instructors had a positive view of RI. The dental school-related RI education index was formed by averaging the responses to these five items. The mean index showed that the respondents disagreed on average that they were well educated about RI in dental school. However, the scores ranged from $1=$ disagree strongly to $5=$ agree strongly. 
Table 1. Participants' personal, professional, and practice characteristics, by number and percentage of total respondents $(\mathrm{N}=273)$

\begin{tabular}{|c|c|c|}
\hline Characteristic & Number & Percentage \\
\hline \multicolumn{3}{|l|}{ Gender } \\
\hline Men & 151 & $56 \%$ \\
\hline Women & 118 & $44 \%$ \\
\hline Community location of practice & 8 & $3 \%$ \\
\hline Rural $(<5,000)$ & 34 & $13 \%$ \\
\hline Small town/city $(5,000-24,999)$ & 73 & $27 \%$ \\
\hline Moderate-sized city $(25,000-250,000)$ & 95 & $35 \%$ \\
\hline \multirow{2}{*}{$\begin{array}{l}\text { Suburb near large city } \\
\text { Large city }\end{array}$} & 59 & $22 \%$ \\
\hline & Mean & SD, Range \\
\hline Age & 46.75 & $13,25-74$ \\
\hline Year of graduation from dental school & 1997 & $14.293,1967-2016$ \\
\hline \multirow[t]{2}{*}{ Year of graduation from pediatric residency program } & 2000 & $14.379,1969-2020$ \\
\hline & Mean \% & SD, Range \\
\hline \multicolumn{3}{|l|}{ How professional time spent } \\
\hline Office practice & $76 \%$ & $27,0-100 \%$ \\
\hline Teaching & $8 \%$ & $21,0-100 \%$ \\
\hline Operating room & $8 \%$ & $13,0-100 \%$ \\
\hline Administration & $6 \%$ & $12,0-100 \%$ \\
\hline \multicolumn{3}{|l|}{ Practice type and role } \\
\hline Solo practice & $30 \%$ & $46,0-100 \%$ \\
\hline Group practice & $39 \%$ & $49,0-100 \%$ \\
\hline Associate & $16 \%$ & $37,0-100 \%$ \\
\hline Partner & $8 \%$ & $27,0-100 \%$ \\
\hline Owner & $24 \%$ & $43,0-100 \%$ \\
\hline Public health & $13 \%$ & $33,0-100 \%$ \\
\hline Other & $10 \%$ & $30,0-100 \%$ \\
\hline \multicolumn{3}{|l|}{ Patients covered by } \\
\hline Medicaid & $38 \%$ & $36 \%, 0-100 \%$ \\
\hline Private insurance & $45 \%$ & $30 \%, 0-100 \%$ \\
\hline Self-pay & $14 \%$ & $19 \%, 0-100 \%$ \\
\hline Other & $1 \%$ & $8 \%, 0-100 \%$ \\
\hline
\end{tabular}

Five questions were related to the respondents' education about RI during their pediatric dentistry residency. A total of $24 \%$ agreed/agreed strongly that their classroom-based residency education had informed them about the use of RI and 22\% that it had informed them about its benefits. Only $9 \%$ reported that their clinical residency education had prepared them well to use RI with adult patients and $12 \%$ that it had prepared them well to use RI with pediatric patients. When asked about their residency program instructors' views of RI and MID, 17\% agreed/agreed strongly that their instructors had a positive view of the use of RI, and 39\% that their instructors had a positive view of MID procedures.

When asked how much they had heard about RI after their formal dental education, $36 \%$ of the respondents were neutral, $36 \%$ said they had heard a great deal about it, 54\% said they had heard some information, and $9 \%$ said they never heard about RI after graduation. However, 48\% reported (agreed/ agreed strongly) that they had taken a continuing education (CE) course about the use of minimally invasive procedures for treating carious lesions and $29 \%$ about the use of RI. In addition, $59 \%$ said they would like to take a course about RI, and $71 \%$ would like to learn more about the use of RI. A large majority $(86 \%)$ said they had read an article about the use of MID procedures for treating caries, and $76 \%$ had read an article about the use of RI.

The majority agreed/strongly agreed with five of the six positive items: that the use of RI helps avoid the use of local anesthesia with pediatric patients $(72 \%)$, helps with the restoration of non-cavitated lesions $(71 \%)$, has aesthetic benefits $(70 \%)$, prolongs 
Table 2. Respondents' educational experiences related to resin infiltration (RI) and minimally invasive dentistry (MID), by percentage of total respondents $(\mathrm{N}=273)$

\begin{tabular}{|c|c|c|c|c|c|c|}
\hline Variable & $\begin{array}{l}\text { Disagree } \\
\text { Strongly }\end{array}$ & Disagree & Neutral & Agree & $\begin{array}{l}\text { Agree } \\
\text { Strongly }\end{array}$ & Mean \\
\hline \multicolumn{7}{|l|}{ Dental school education about RI } \\
\hline a. My classroom-based education informed me about the use of RI. & $71 \%$ & $12 \%$ & $8 \%$ & $6 \%$ & $3 \%$ & 1.56 \\
\hline $\begin{array}{l}\text { b. My classroom-based education informed me about the benefits } \\
\text { of using RI. }\end{array}$ & $73 \%$ & $12 \%$ & $8 \%$ & $4 \%$ & $2 \%$ & 1.51 \\
\hline $\begin{array}{l}\text { C. My clinical education prepared me well to use RI with adult } \\
\text { patients. }\end{array}$ & $78 \%$ & $12 \%$ & $8 \%$ & $0.4 \%$ & $1 \%$ & 1.34 \\
\hline $\begin{array}{l}\text { d. My clinical education prepared me well to use RI with } \\
\text { pediatric patients. }\end{array}$ & $78 \%$ & $13 \%$ & $8 \%$ & $0.4 \%$ & $0.4 \%$ & 1.32 \\
\hline e. My instructors had a positive view of RI. & $57 \%$ & $15 \%$ & $25 \%$ & $2 \%$ & $2 \%$ & 1.78 \\
\hline $\begin{array}{l}\text { Dental school-related RI education index (Cronbach's } \\
\text { alpha }=0.910)\end{array}$ & \multicolumn{2}{|c|}{ Mean $=1.50$} & \multicolumn{2}{|c|}{$\mathrm{SD}=0.77$} & \multicolumn{2}{|c|}{ Range: $1-5$} \\
\hline \multicolumn{7}{|l|}{ Pediatric dentistry residency education about RI } \\
\hline f. My classroom-based education informed me about the use of RI. & $53 \%$ & $9 \%$ & $13 \%$ & $15 \%$ & $9 \%$ & 2.18 \\
\hline $\begin{array}{l}\text { g. My classroom-based education informed me about the benefits } \\
\text { of using RI. }\end{array}$ & $54 \%$ & $9 \%$ & $16 \%$ & $14 \%$ & $8 \%$ & 2.13 \\
\hline $\begin{array}{l}\text { h. My clinical education prepared me well to use RI with adult } \\
\text { patients. }\end{array}$ & $62 \%$ & $14 \%$ & $15 \%$ & $5 \%$ & $4 \%$ & 1.74 \\
\hline $\begin{array}{l}\text { i. My clinical education prepared me well to use RI with } \\
\text { pediatric patients. }\end{array}$ & $60 \%$ & $14 \%$ & $15 \%$ & $8 \%$ & $4 \%$ & 1.81 \\
\hline j. My instructors had a positive view of the use of RI. & $45 \%$ & $11 \%$ & $26 \%$ & $11 \%$ & $6 \%$ & 2.21 \\
\hline Residency-related RI education index (Cronbach's alpha=0.946) & \multicolumn{2}{|c|}{ Mean=2.01 } & \multicolumn{2}{|c|}{$\mathrm{SD}=1.16$} & \multicolumn{2}{|c|}{ Range: 1 to 5} \\
\hline \multicolumn{7}{|l|}{ MID-related educational experiences } \\
\hline $\begin{array}{l}\text { k. My dental school instructors had a positive view of MID } \\
\text { procedures. }\end{array}$ & $34 \%$ & $21 \%$ & $23 \%$ & $13 \%$ & $11 \%$ & 2.46 \\
\hline $\begin{array}{l}\text { I. My residency instructors had a positive view of MID } \\
\text { procedures. }\end{array}$ & $26 \%$ & $11 \%$ & $24 \%$ & $21 \%$ & $18 \%$ & 2.94 \\
\hline MID-related education index (Cronbach's alpha=0.745) & \multicolumn{2}{|c|}{ Mean $=2.71$} & \multicolumn{2}{|c|}{$\mathrm{SD}=1.25$} & \multicolumn{2}{|c|}{ Range: 1 to 5} \\
\hline \multicolumn{7}{|l|}{ Professional experiences and education } \\
\hline $\begin{array}{l}\text { m. How much have you heard about RI and using it? } \\
\text { I took CE courses about: }\end{array}$ & $9 \%$ & - & $54 \%$ & - & $36 \%$ & 3.56 \\
\hline $\mathrm{n}$. The use of MID procedures for treating caries. & $30 \%$ & $9 \%$ & $13 \%$ & $28 \%$ & $20 \%$ & 2.98 \\
\hline o. The use of RI. & $40 \%$ & $14 \%$ & $16 \%$ & $19 \%$ & $10 \%$ & 2.47 \\
\hline Professional education index (Cronbach's alpha=0.757) & \multicolumn{2}{|c|}{ Mean=3.10 } & \multicolumn{2}{|c|}{$\mathrm{SD}=1.102$} & \multicolumn{2}{|c|}{ Range: 1.67 to 4.33} \\
\hline \multicolumn{7}{|l|}{ Motivation to learn more about RI } \\
\hline p. I would like to take a CE course about RI. & $7 \%$ & $8 \%$ & $22 \%$ & $30 \%$ & $29 \%$ & 3.71 \\
\hline q. I would like to learn more about the use of RI. & $2 \%$ & $4 \%$ & $13 \%$ & $34 \%$ & $37 \%$ & 4.45 \\
\hline Motivation to learn more about RI index (Cronbach's alpha=0.818) & \multicolumn{2}{|c|}{ Mean=3.89 } & \multicolumn{2}{|c|}{$\mathrm{SD}=0.99$} & \multicolumn{2}{|c|}{ Range: 1 to 5} \\
\hline \multicolumn{7}{|l|}{ In the past years, I read an article about } \\
\hline r. The use of MID procedures for treating caries. & $4 \%$ & $2 \%$ & $8 \%$ & $37 \%$ & $49 \%$ & 4.26 \\
\hline s. The use of RI. & $10 \%$ & $4 \%$ & $10 \%$ & $40 \%$ & $36 \%$ & 3.86 \\
\hline $\begin{array}{l}\text { Previous self-education about RI/MID index (Cronbach's } \\
\text { alpha }=0.803 \text { ) }\end{array}$ & \multicolumn{2}{|c|}{ Mean=4.06 } & \multicolumn{2}{|c|}{$\mathrm{SD}=1.01$} & \multicolumn{2}{|c|}{ Range: 1 to 5} \\
\hline
\end{tabular}

Note: Means were based on the following numerical scale: $1=$ disagree strongly, $2=$ disagree, $3=$ neutral, $4=$ agree, and $5=$ agree strongly. The dental school-related RI education index was computed by averaging the responses to items a to e. The residency-related RI education index was computed by averaging the responses to items $\mathrm{f}$ to $\mathrm{j}$. The MID-related education index was computed by averaging the responses to items $\mathrm{k}$ and $\mathrm{I}$. The professional education index was computed by averaging the responses to items $\mathrm{m}$ to $\mathrm{o}$. The motivation to learn more about RI index was computed by averaging the items $\mathrm{p}$ and $\mathrm{q}$. The previous self-education about RI/MID index was computed by averaging the responses to items $r$ and $s$.

aResponse options on this item were $1=$ never heard of it, $3=$ have heard of it somewhat, and $5=$ have heard a great deal on the matter.

the life expectancy of a tooth $(65 \%)$, and is useful in their practice (60\%) (Table 3). In addition, $49 \%$ agreed/agreed strongly that the use of RI helps prevent dental fear in their patients. On the other hand,
$4 \%$ agreed/agreed strongly that RI is only of value in orthodontic practices, $6 \%$ that they did not believe in MID, $11 \%$ that RI is a fad that will disappear again, and $16 \%$ that RI is not practical for them to use. 
Table 3. Respondents' attitudes about use of resin infiltration (RI), by percentage of total respondents $(\mathrm{N}=\mathbf{2 7 3})$

\begin{tabular}{|c|c|c|c|c|c|c|}
\hline Variable & $\begin{array}{l}\text { Disagree } \\
\text { Strongly }\end{array}$ & Disagree & Neutral & Agree & $\begin{array}{l}\text { Agree } \\
\text { Strongly }\end{array}$ & Mean \\
\hline \multicolumn{7}{|l|}{ Positive attitude towards RI } \\
\hline a. The use of RI has esthetic benefits. & $4 \%$ & $2 \%$ & $26 \%$ & $34 \%$ & $36 \%$ & 3.95 \\
\hline $\begin{array}{l}\text { b. The use of RI helps to avoid use of local anesthesia for } \\
\text { pediatric patients. }\end{array}$ & $3 \%$ & $6 \%$ & $20 \%$ & $37 \%$ & $35 \%$ & 3.95 \\
\hline c. The use of RI helps with restoration of non-cavitated lesions. & $1 \%$ & $4 \%$ & $23 \%$ & $37 \%$ & $34 \%$ & 3.99 \\
\hline d. The use of RI helps to prolong the life expectancy of a tooth. & $2 \%$ & $5 \%$ & $28 \%$ & $32 \%$ & $33 \%$ & 3.89 \\
\hline e. The use of RI helps me to prevent dental fear in my patients. & $3 \%$ & $11 \%$ & $37 \%$ & $26 \%$ & $23 \%$ & 3.55 \\
\hline f. This technique is useful in my practice (or can be). & $3 \%$ & $7 \%$ & $31 \%$ & $33 \%$ & $27 \%$ & 3.73 \\
\hline Positive attitude towards RI index (Cronbach's alpha=0.904) & \multicolumn{2}{|c|}{ Mean $=3.84$} & \multicolumn{2}{|c|}{$\mathrm{SD}=0.822$} & \multicolumn{2}{|c|}{ Range: 1 to 5} \\
\hline \multicolumn{7}{|l|}{ Negative attitude towards RI } \\
\hline g. I don't believe in minimally invasive dentistry. & $71 \%$ & $14 \%$ & $9 \%$ & $4 \%$ & $2 \%$ & 1.51 \\
\hline h. RI is a fad that will disappear again. & $30 \%$ & $25 \%$ & $34 \%$ & $10 \%$ & $1 \%$ & 2.27 \\
\hline i. It is not practical for me to use RI. & $24 \%$ & $24 \%$ & $36 \%$ & $12 \%$ & $4 \%$ & 2.47 \\
\hline j. RI is only of value in orthodontic practices. & $47 \%$ & $28 \%$ & $22 \%$ & $3 \%$ & $1 \%$ & 1.83 \\
\hline Negative attitude towards RI index (Cronbach's alpha=0.719) & \multicolumn{2}{|c|}{ Mean=2.02 } & \multicolumn{2}{|c|}{$\mathrm{SD}=0.739$} & \multicolumn{2}{|c|}{ Range: 1 to 4} \\
\hline \multicolumn{7}{|l|}{ Responses related to RI use } \\
\hline I would consider implementing RI in my clinic. & $4 \%$ & $7 \%$ & $23 \%$ & $39 \%$ & $25 \%$ & 3.74 \\
\hline $\begin{array}{l}\text { The fact that RI does not show up on radiographs is a problem } \\
\text { for me. }\end{array}$ & $7 \%$ & $10 \%$ & $24 \%$ & $37 \%$ & $22 \%$ & 3.56 \\
\hline Frequency of use & Never & Sometimes & Often & Very Often & & Mean \\
\hline How often do you use RI in your own work? & $69 \%$ & $28 \%$ & $3 \%$ & $1 \%$ & & 1.36 \\
\hline
\end{tabular}

When asked if they would consider implementing RI in their own clinic, 64\% agreed/agreed strongly that they would consider implementing it. However, 59\% agreed/agreed strongly that the fact that RI does not show up on radiographs is a problem for them. In response to the question how often they used RI in their own work, $69 \%$ responded that they never used it, $28 \%$ that they sometimes used it, $3 \%$ that they often used it, and $1 \%$ that they very often used it.

Table 4 shows the number of positive and negative open-ended responses related to RI. The most frequent positive responses were related to the fact that the respondents liked minimally invasive methods to arrest caries, that no tooth preparation was needed, and that RI has aesthetic benefits in the anterior region, can be used without a local anesthetic, and is easy for the patient and the dentist. The most frequently named "dislike" was that RI does not show up on radiographs, followed by answers related to RI not having reliable results and not being reimbursed by insurance.

The more recently the respondents had graduated from dental school and from their residency program, the better they were educated about RI in dental school, in their residency program, and about MID (Table 5). However, year of graduation did not correlate with the respondents' educational experiences after graduation, their motivation to learn more about these subject matters, nor their own self-education efforts in this area. In addition, while the dental school, residency, and MID-related educational indices were intercorrelated, they did not correlate with the professional education, motivational, and self-education indices. However, the motivational and self-education indices did correlate significantly with the respondents' attitudes. In addition, the residency education index, the professional education index, and the self-education index correlated significantly with the frequency of RI use in their own work.

The respondents' graduation year from dental school and their residency programs did not correlate significantly with their RI-related attitudes and behavior (Table 6). However, their attitudes were positively associated with their RI-related behavioral responses. 
Table 4. Number of open-ended resin infiltration (RI)-related responses, by rater

\begin{tabular}{|c|c|c|}
\hline Response & Rater 1 & Rater 2 \\
\hline \multicolumn{3}{|l|}{ Positive responses: "likes" } \\
\hline Minimally invasive method to arrest caries & 74 & 68 \\
\hline No tooth preparation needed using bur or noise from the bur & 41 & 38 \\
\hline Aesthetic benefits in anterior area & 27 & 28 \\
\hline Can be used without local anesthetic & 21 & 20 \\
\hline Easy for patient/not painful & 21 & 19 \\
\hline Easy for dentist & 19 & 16 \\
\hline Arresting carious lesions or prevention & 8 & 8 \\
\hline Under right circumstances, it can be beneficial & 4 & 2 \\
\hline Another technique to add to our armamentarium & 2 & 3 \\
\hline Don't know, unsure, or N/A & 21 & 21 \\
\hline Total & 238 & 223 \\
\hline Consistency \% & $87 \%$ & $90 \%$ \\
\hline \multicolumn{3}{|l|}{ Negative responses: "dislikes" } \\
\hline Does not show up on radiographs & 48 & 47 \\
\hline Not reliable or inconsistent results & 25 & 24 \\
\hline Not reimbursed by insurance (no code or charge) & 24 & 25 \\
\hline Time & 24 & 24 \\
\hline More technique-sensitive than other MI treatments & 21 & 20 \\
\hline Patient follow-up compliance & 11 & 8 \\
\hline Needs rubber dam & 12 & 3 \\
\hline Not enough research on RI & 9 & 10 \\
\hline Inadequate interproximal access & 9 & 9 \\
\hline $\mathrm{RI}$ is expensive & 7 & 8 \\
\hline $\begin{array}{l}\text { Technical issues (not easy to use; continually have to watch; } \\
\text { removes tooth surface w/ acid etch) }\end{array}$ & 5 & 4 \\
\hline $\begin{array}{l}\text { Not enough right circumstances/indications; practicality of its } \\
\text { use in public health not logical }\end{array}$ & 5 & 4 \\
\hline Not comfortable/confident in recommending & 4 & 5 \\
\hline Parent issues/difficult to explain to parent & 5 & 3 \\
\hline Patient experiences pain without LA & 3 & 3 \\
\hline No good aesthetic benefits for some lesions & 2 & 2 \\
\hline Non-compliant or fearful kids & 1 & 3 \\
\hline Not for primary teeth (going to lose anyway) & 1 & 1 \\
\hline Don't know, unsure, or N/A & 25 & 25 \\
\hline Total & 241 & 228 \\
\hline Consistency \% & $90 \%$ & $93 \%$ \\
\hline
\end{tabular}

\section{Discussion}

According to the a priori power analysis, data from 262 respondents were needed to have the power to determine if there was a positive relationship between the respondents' RI-related educational experiences and RI-related attitudes and behavior. Data from 273 respondents were collected, which ensured that this study had a sufficiently large sample size to test hypotheses about relationships between the constructs of interest. In addition, the response rate achieved in this study was $11.75 \%$. This response rate slightly exceeds the response rate for web-based surveys that Hardigan et al. achieved in their quasiexperimental study with dentists concerning the response rates to paper-pencil vs. web-based surveys. ${ }^{28}$ Also, an analysis of the demographic and practice characteristics of the participating pediatric dentists as well as the responses concerning RI-related educational experiences, attitudes, and behavior showed that the sample was quite heterogeneous and was not biased towards a specific group of respondents.

An analysis of the respondents' RI-related educational experiences showed that while RI was not at all well covered in their dental school curricula, more than one in five respondents had RI-related classroom-based experiences in their residency 
Table 5. Relationships between educational experiences related to resin infiltration (RI) and minimally invasive dentistry (MID), RI-related attitudes, and RI use

\begin{tabular}{|c|c|c|c|c|c|c|}
\hline & $\begin{array}{c}\text { A } \\
\text { Dental } \\
\text { School }\end{array}$ & $\begin{array}{c}\text { B } \\
\text { Residency }\end{array}$ & $\begin{array}{c}\text { C } \\
\text { MID- } \\
\text { Related }\end{array}$ & $\begin{array}{c}\text { D } \\
\text { Professional }\end{array}$ & $\underset{\text { Motivation }}{E}$ & 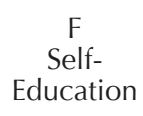 \\
\hline \multicolumn{7}{|l|}{ Education } \\
\hline Year completed dental school & $0.36^{* * *}$ & $0.62^{* * *}$ & $0.54^{* * *}$ & -0.07 & 0.04 & -0.06 \\
\hline Year completed pediatric dental residency & $0.35^{* * *}$ & $0.61^{* * *}$ & $0.54^{* * *}$ & -0.05 & 0.04 & -0.06 \\
\hline \multicolumn{7}{|l|}{ RI-related educational indices } \\
\hline $\mathrm{A}=$ dental school-related RI education index & 1 & $0.61^{* * *}$ & $0.52^{* * *}$ & 0.05 & $-0.14^{*}$ & -0.01 \\
\hline $\mathrm{B}=$ residency-related $\mathrm{RI}$ education index & $0.61 * * *$ & 1 & $0.59 * * *$ & 0.09 & -0.07 & 0.04 \\
\hline $\mathrm{C}=\mathrm{MID}$-related education index & $0.52 * * *$ & $0.59 * * *$ & 1 & 0.023 & -0.09 & 0.01 \\
\hline $\mathrm{D}=$ professional education index & 0.05 & 0.09 & 0.03 & 1 & 0.02 & $0.38^{* * *}$ \\
\hline $\mathrm{E}=$ motivation to learn more about $\mathrm{RI}$ index & $-0.14^{*}$ & -0.07 & -0.09 & 0.02 & 1 & $0.13^{*}$ \\
\hline $\mathrm{F}=$ previous RI/MID-related self-education index & -0.01 & 0.04 & 0.01 & $0.38^{* * *}$ & $0.13^{*}$ & 1 \\
\hline \multicolumn{7}{|l|}{ RI-related attitudinal indices } \\
\hline $\mathrm{G}=$ positive attitude towards RI index & -0.04 & 0.06 & -0.03 & $0.15^{*}$ & $0.55^{* * *}$ & $0.23 * * *$ \\
\hline $\mathrm{H}=$ negative attitude towards $\mathrm{RI}$ index & 0.02 & -0.11 & -0.11 & $-0.17^{*}$ & $-0.40^{* * *}$ & $-0.19 * *$ \\
\hline \multicolumn{7}{|l|}{ RI-related behavior } \\
\hline I would consider implementing RI in my clinic ${ }^{a}$ & -0.01 & 0.11 & 0.002 & 0.07 & $0.57^{* * *}$ & $0.14 *$ \\
\hline Frequency of using Rl in my own work ${ }^{b}$ & 0.07 & $0.20^{* *}$ & 0.003 & $0.34^{* * *}$ & -0.03 & $0.30^{* * *}$ \\
\hline
\end{tabular}

Note: The dental school-related RI education index (A) was computed by averaging the responses to items a to e in Table 2 . The residency-related RI education index (B) was computed by averaging the responses to items $f$ to $j$ in Table 2 . The MID-related education index (C) was computed by averaging the responses to items $\mathrm{k}$ and $\mathrm{l}$ in Table 2. The professional education index (D) was computed by averaging the responses to items $\mathrm{m}$ to $\mathrm{o}$ in Table 2 . The motivation to learn more about RI index (E) was computed by averaging the items $\mathrm{p}$ and $\mathrm{q}$ in Table 2. The previous RI/MID-related self-education index $(\mathrm{F})$ was computed by averaging the responses to items $\mathrm{r}$ and $\mathrm{s}$ in Table 2. The positive attitude towards RI index (G) was computed by averaging the responses to items a to $f$ in Table 3 . The negative attitude towards RI index $(\mathrm{H})$ was computed by averaging the responses to items $g$ to $\mathrm{j}$ in Table 3 . The question to determine frequency of using RI was worded as "How often do you use RI in your own work?"

${ }^{a}$ Response options were $1=$ disagree strongly, $2=$ disagree, $3=$ neutral, $4=$ agree, and $5=$ agree strongly.

${ }^{\mathrm{b}}$ Response options were $1=$ never, $2=$ sometimes, $3=$ often, and $4=$ very often.

${ }^{*} \mathrm{p}<0.05,{ }^{* *} \mathrm{p}<0.01,{ }^{* * *} \mathrm{p}<0.001$

Table 6. Relationships between attitudes about resin infiltration (RI) and RI use and respondents' characteristics

\begin{tabular}{|c|c|c|c|c|}
\hline Characteristic & $\begin{array}{c}\mathrm{G}=\text { Positive } \\
\text { Attitude Towards } \\
\text { RI Index }\end{array}$ & $\begin{array}{c}\mathrm{H}=\text { Negative } \\
\text { Attitude Towards } \\
\text { RI Index }\end{array}$ & $\begin{array}{l}\text { I Would Consider } \\
\text { Implementing RI } \\
\text { in My Clinic }\end{array}$ & $\begin{array}{c}\text { Frequency of } \\
\text { Using RI in } \\
\text { Own Work }\end{array}$ \\
\hline Year completed dental school & 0.07 & -0.18 & $0.15^{*}$ & 0.06 \\
\hline Year completed pediatric dentistry residency & 0.08 & -0.21 & $0.15^{*}$ & 0.08 \\
\hline \multicolumn{5}{|l|}{ RI-related attitudinal indices } \\
\hline $\mathrm{G}=$ positive attitude towards $\mathrm{RI}$ index & 1 & $-0.49 * * *$ & $0.64 * * *$ & $0.17^{* *}$ \\
\hline $\mathrm{H}=$ negative attitude towards $\mathrm{RI}$ index & $-0.50 * * *$ & 1 & $-0.59 * * *$ & $-0.38^{* * *}$ \\
\hline \multicolumn{5}{|l|}{ RI-related behavior } \\
\hline I would consider implementing RI in my clinic ${ }^{a}$ & $0.64^{* * *}$ & $-0.59 * * *$ & 1 & $0.21^{* * *}$ \\
\hline Frequency of using RI in my own work ${ }^{b}$ & $0.17^{* *}$ & $-0.38^{* * *}$ & $0.21^{* * *}$ & 1 \\
\hline
\end{tabular}

Note: The positive attitude towards RI index (G) was computed by averaging the responses to items a to $\mathrm{f}$ in Table 3 . The negative attitude towards RI index $(\mathrm{H})$ was computed by averaging the responses to items $\mathrm{g}$ to $\mathrm{j}$ in Table 3 . The question to determine frequency of using RI was worded as "How often do you use RI in your own work?"

aResponse options were $1=$ disagree strongly, $2=$ disagree, $3=$ neutral, $4=$ agree, and $5=$ agree strongly.

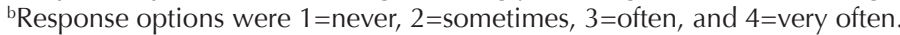

${ }^{*} \mathrm{p}<0.05,{ }^{* *} \mathrm{p}<0.01,{ }^{* * *} \mathrm{p}<0.001$ 
programs, with fewer reporting clinical experiences (Table 2). These percentages are not surprising because RI has only recently become a more accepted new treatment option for interproximal incipient carious lesions..$^{29,30}$ However, the findings that 59\% agreed/agreed strongly that they would like to take a CE course about RI, that $71 \%$ would like to learn more about RI, and that $76 \%$ read an article about RI are noteworthy and have clear implications for changes in predoctoral dental curricula and pediatric dentistry graduate programs. However, these findings should also be considered in the context of the negative open-ended remarks that were made. In consideration of these negative comments, it is possible that the motivation to attend a CE course about RI might be due to the challenges considered when using this method.

In interpreting these results, it is important to consider when the respondents graduated from dental school and from their pediatric residency program because the Infiltration Concept (ICON) material used for RI treatment was not introduced in the U.S. until 2009. ${ }^{31}$ It is therefore not surprising that these two graduation years were significantly correlated with respondents' evaluation of their dental school, residency, and MID-related education (Table 5). However, one interesting finding in this context is that graduation years were not significantly correlated with the respondents' professional education nor with their motivation to learn more about RI and their own previous RI/MID-related self-education efforts. This finding shows that the professional education considerations were independent of the respondents' age. In addition, the finding of a positive correlation between the two graduation years and the respondents' willingness to consider implementing $\mathrm{RI}$ in their own practice deserves attention. It implies that $\mathrm{CE}$ efforts should be targeted towards pediatric dentists in all age groups.

Consistent with this interest in learning more about RI were the quite positive attitudes of the responding pediatric dentists (Table 3), with the majority agreeing/strongly agreeing with five of the six positive attitudinal statements. These findings are especially interesting when considering that previous research on dentists' attitudes about minimally invasive treatment methods found that attitudes ranged widely from some dentists believing that there was no strong evidence to support these technique to others arguing that minimally invasive treatment approaches were superior in some instances. ${ }^{10,11,21,32}$
A recent study by Schwendicke et al. in New Zealand, Germany, and the U.S. concerning dentists' decision making when managing non-cavitated lesions explored this topic by conducting in-depth interviews. ${ }^{33}$ Use of this qualitative method resulted in rich findings about the wide range of dentists' considerations concerning minimally invasive techniques including RI. Gaining a solid understanding of these considerations is crucial because they may ultimately determine the utilization of these approaches in dentists' daily clinical practice. In our study, the responses to open-ended questions concerning what the respondents liked vs. disliked about RI were similarly interesting. The fact that RI is a minimally invasive technique was mentioned most frequently as a positive feature, with a focus on patient-friendly aspects of this technique following. The fact that a treatment with RI does not show up on radiographs was by far the most frequently mentioned concern. Two of the next most frequently mentioned concerns were that a treatment with RI would have nonreliable or inconsistent results and be time-consuming. Concerning this first set of responses, it is important to note that a number of high-quality studies, such as systematic reviews $\mathrm{s}^{34,35}$ and randomized controlled trials, ${ }^{36-38}$ have reported the efficacy of RI treatment over a treatment with fluoride varnish or regular care consisting of observing the lesions only. A discussion of the concern over time needed for a treatment with RI needs to consider the results of a study by Altarabulsi et al. in 2013. ${ }^{39}$ These authors did not only find good patient satisfaction with the procedure, but had a mean time for infiltration of $24.3 \pm 7.4$ minutes, which included rubber dam application $(7.7 \pm 4 \mathrm{~min}-$ utes). They reported that clinicians perceived the RI-related treatment to be comparable or even easier than a composite filling.

Given these newer findings, it is possible that the respondents in our study who listed these reasons for disliking RI may not have been aware of this empirical evidence that RI is an effective method to arrest incipient carious lesions. ${ }^{11}$ They may not have known that when RI treatment is associated with fluoride therapy, it is more effective in preventing carious lesions than fluoride therapy alone in deciduous teeth. ${ }^{29,30}$ In addition, RI has proven benefits in preventing interproximal carious lesions progression similar to dental sealants' efficacy in occlusal surfaces. ${ }^{40}$ The implications then might be that solid classroom-based as well as clinical education about $\mathrm{RI}$ is needed to ensure that this technique receives the attention it deserves. 
Given the strong relationships we found between professional attitudes and behavior, attempts should be made to engage faculty members in intensive faculty development activities concerning the use of RI. Educators in dental schools as well as in pediatric dentistry residency programs should be knowledgeable about the currently available evidence concerning the benefits of using RI. ${ }^{19,20}$ However, given the potential conflict of interest created when past research was funded by industry support, ${ }^{19}$ future research is needed that does not depend on that form of support. Meanwhile, classroom-based and clinical opportunities to introduce predoctoral and advanced dental students to RI should be explored.

This study had three limitations. First, this study focused on pediatric dentists because RI has clear benefits when providing care for potentially fearful children. Future research should assess general dentists' thoughts concerning the use of this technique for the treatment of adult patients. Second, it would have been interesting to compare the responses of subgroups of respondents, such as by practice type. However, the subgroup sample sizes were too small to compare the average response of various groups. Future research should consider these research questions related to pediatric dentists' practice situations and how they might affect their RI-related professional behavior. Third, while the response rate to this web-based survey was acceptable, it cannot be ruled out that these respondents were more likely to have heard about RI than pediatric dentists in general.

\section{Conclusion}

Based on these data, we can draw the following conclusions. First, while the study found that the respondents' dental school curricula did not include much education about RI in classroom-based and clinical settings, their pediatric dentistry graduate programs were more likely to educate residents about this technique. This finding is consistent with the finding that while only a small percentage of dental school faculty members were perceived as being positive towards this technique, about four out of ten residency program faculty members were described as having had a positive view of RI. Second, questions concerning the respondents' professional education showed that the majority would like to take a CE course about RI and would like to learn more about RI; also, more than three out of four had read an article about MID and an article about the use of
RI. Third, the respondents' attitudes towards RI were quite positive, and more than six out of ten respondents said they would consider implementing RI in their practice. Fourth, over three out of ten respondents used RI in their own work at least sometimes. Finally, concerning the educational implications of these findings, the data showed that the more recently respondents had graduated from their dental school and residency program, the more education about MID and RI they had received. However, there was a strong interest in continuing education about RI that deserves attention. The question therefore is whether dental school and specialty program faculty members share the positive attitudes towards RI and will be able to provide the needed education.

\section{Acknowledgments}

We would like to thank the American Academy of Pediatric Dentistry (AAPD) for providing us with the email addresses of its members and to thank the respondents who took time out of their busy schedules to support this research.

\section{REFERENCES}

1. Dye BA, Mitnik GL, Iafolla TJ, Vargas CM. Trends in dental caries in children and adolescents according to poverty status in the United States from 1999 through 2004 and from 2011 through 2014. J Am Dent Assoc 2017;148(8):550-65.

2. Dye BA, Thornton-Evans G, Li X, Iafolla TJ. Dental caries and sealant prevalence in children and adolescents in the United States, 2011-12. NCHS data brief, no. 191. Hyattsville, MD: National Center for Health Statistics, 2015.

3. $\mathrm{Ng} \mathrm{C}$. What's your philosophy: maximally destructive or minimally invasive dentistry? Br Dent J 2018;225:420-4.

4. Ismail AI, Pitts NB, Tellez M. The international caries classification and management system (ICCMSTM): an example of a caries management pathway. BMC Oral Health 2015;15(Suppl 1):S9.

5. Elgreatly A. Management of initial caries lesions: Iowa survey. Master of science thesis, University of Iowa, 2017. At: doi.org/10.17077/etd.44iqxuod. Accessed 11 March 2019.

6. Griffin S, Oong E, Kohn W, et al. The effectiveness of sealants in managing caries lesions. J Dent Res 2008;87(2):169-74.

7. American Dental Association, Center for Evidence-Based Dentistry. Nonrestorative treatments for carious lesions clinical practice guideline (2018). At: ebd.ada.org/en/ evidence/guidelines/nonrestorative-treatments-for-carieslesions. Accessed 11 March 2019.

8. Nainar SH. Resin infiltration technique for proximal caries lesions in the permanent dentition: a contrarian viewpoint. Oper Dent 2014;39(1):1-3.

9. Meyer-Lueckel H, Paris S, Kielbassa AM. Surface layer erosion of natural caries lesions with phosphoric and 
hydrochloric acid gels in preparation for resin infiltration. Caries Res 2007;41(3):223-30.

10. Borges A, Caneppele T, Masterson D, Maia L. Is resin infiltration an effective esthetic treatment for enamel development defects and white spot lesions? A systematic review. J Dent 2017;56(1):11-8.

11. Domejean S, Ducamp RL, Leger SP, Holmgren C. Resin infiltration of non-cavitated caries lesions: a systematic review. Med Princ Pract 2015;24(3):216-21.

12. Gurdogan EB, Ozdemir-Ozenen D, Sandalli N. Evaluation of surface roughness characteristics using atomic force microscopy and inspection of microhardness following resin infiltration with Icon. J Esthet Restor Dent 2017;29(3):201-8.

13. Cazzolla AP, De Franco AR, Lacaita M, Lacarbonara $\mathrm{V}$. Efficacy of 4-year treatment of icon infiltration resin on postorthodontic white spot lesions. BMJ Case Rep 2018;18:2.

14. Ekstrand KR, Bakhshandeh A, Martignon S. Treatment of proximal superficial caries lesions on primary molar teeth with resin infiltration and fluoride varnish versus fluoride varnish only: efficacy after 1 year. Caries Res 2010;44(1):41-6.

15. Meyer-Lueckel H, Bitter K, Paris S. Randomized controlled clinical trial on proximal caries infiltration: threeyear follow-up. Caries Res 2012;46(6):544-8.

16. American Academy of Pediatric Dentistry. Pediatric restorative dentistry: reference manual. Pediatr Dent 2017;39(6):312-24.

17. Son JH, Hur B, Kim HC, Park JK. Management of white spots: resin infiltration technique and microabrasion. J Kor Acad Cons Dent 2011;36(1):66-71.

18. Gencer MDG, Kirzioglu A. A comparison of the effectiveness of resin infiltration and microabrasion treatments applied to developmental enamel defects in color masking. Dent Mater J 2019;38(2):295-302.

19. El Meligy OAEL, Ibrahim STE, Alamoudi NM. Resin infiltration of non-cavitated proximal caries lesions: a literature review. J Oral Hyg Health 2018;6(1):234.

20. Faghihian R, Shirani M, Tarrahi MJ, Zakizade M. Efficacy of the resin infiltration technique in preventing initial caries progression: a systematic review and meta-analysis. Pediatr Dent 2019;41(2):88-94.

21. Kielbassa AM, Müller J, Gernhardt CR. Closing the gap between oral hygiene and minimally invasive dentistry: a review on the resin infiltration technique of incipient (proximal) enamel lesions. Quintessence Int 2009;40(8):663-81.

22. Paris S, Bitter K, Naumann M, et al. Resin infiltration of proximal caries lesions differing in ICDAS codes. Eur J Oral Sci 2011;119(2):182-6.

23. Feigal RJ. Guiding and managing the child dental patient: a fresh look at old pedagogy. J Dent Educ 2001;65(12):1369-77.

24. American Dental Association. CDT-2017: code on dental procedures and nomenclature, effective January 1, 2017. At: www.deltadentalco.com/uploadedFiles/ ProviderFeeSchedules/DDCO_Par_Provider_Documents/
CDT\%202017_Code\%20on\%20Dental\%20Proc Nomenclature $\% \overline{2} 0$ online.pdf. Accessed 11 March 2019.

25. DeVellis RF. Scale development. Thousand Oaks, CA: Sage, 1991.

26. DeVellis RF. Scale development: theory and applications. Thousand Oaks, CA: Sage, 2003.

27. Weisstein EW. Bonferroni correction. MathWorld. At: mathworld.wolfram.com/BonferroniCorrection.html. Accessed 11 March 2019.

28. Hardigan PC, Succar CT, Fleisher JM. An analysis of response rate and economic costs between mail and webbased surveys among practicing dentists: a randomized trial. J Community Health 2012;37:383-94.

29. Meyer-Lueckel H, Paris S. Infiltration of natural caries lesions with experimental resins differing in penetration coefficients and ethanol addition. Caries Res 2010;44(4):408-14.

30. Phark JH, Duarte S Jr, Meyer-Lueckel H, Paris S. Caries infiltration with resins: a novel treatment option for interproximal caries. Compend Contin Educ Dent 2009;30(Spec No 3):13-7.

31. Dental milestones guaranteed. At: www.dmg-america. com/en/company/about-us/milestones/\#top. Accessed 16 Aug. 2019.

32. Neres EY, Moda M, Chiba E, et al. Microhardness and roughness of infiltrated white spot lesions submitted to different challenges. Oper Dent 2017;42(4):428-35.

33. Schwendicke F, Frencken JE, Bjørndal L, et al. Managing carious lesions: consensus recommendations on carious tissue removal. Adv Dent Res 2016;28(2):58-67.

34. Liang Y, Deng Z, Dai X, et al. Micro-invasive interventions for managing non-cavitated proximal caries of different depths: a systematic review and meta-analysis. Clin Oral Investig 2018;22(8):2675-84.

35. Chatzimarkou S, Koletsi D, Kavvadia K. The effect of resin infiltration on proximal caries lesions in primary and permanent teeth: a systematic review and meta-analysis of clinical trials. J Dent 2018;177(S1):8-17.

36. Ammari MM, Jorge RC, Souza IPR, Soviero VM. Efficacy of resin infiltration of proximal caries in primary molars: 1-year follow-up of a split-mouth randomized controlled clinical trial. Clin Oral Investig 2018;22(3):1355-62.

37. Arthur RA, Zenkner JE, d'Ornellas Pereira Júnior JC, et al. Proximal carious lesions infiltration: a 3-year follow-up study of a randomized controlled clinical trial. Clin Oral Investig 2018;22(1):469-74.

38. Turska-Szybka A, Gozdowski D, Mierzwińska-Nastalska E, Olczak-Kowalczyk D. Randomized clinical trial on resin infiltration and fluoride varnish vs. fluoride varnish treatment only of smooth-surface early caries lesions in deciduous teeth. Oral Health Prev Dent 2016;14(6): 485-91.

39. Altarabulsi MB, Alkilzy M, Splieth CH. Clinical applicability of resin infiltration for proximal caries. Quintessence Int 2013;44(2):97-104.

40. Ermis RB, Yildirim D, Yildiz G, et al. Radiopacity evaluation of contemporary resin composites by digitization of images. Eur J Dent 2014;8(3):342-7. 